of establishment and upkeep, will be ten millions a year, and then if a local authority wish to build a sanatorium they are faced with the express declaration of Dr. Cox's College of Physicians - that it is an extravagant and impossible outlay for a country like this.

The only real effect of the Bill will be to drive patients from the physician to the quack. There will be compulsion on the doctor to notify every consumptive who comes before him, but none on the consumptive to go to the doctor; he can roam at large and go where he will, spreading contagion as heretofore, impossibile to check as long as he avoids the physician. The latter may indeed be called in at the end, but only when curative or preventive measures are alike futile. If it is granted, then, that compulsory notification can only do practical good when all cases of phthisis are notified, what percentage of people will present themselves for notification in a country where already nearly a quarter of the people die without calling in the doctor?

I am, Sir, yours faithfully,

Dublin, Oot. Ath, 1908.

J. C. MCWALTER.

\section{THE FEEDING OF ELEMENTARY SCHOOL CHILDREN.}

To the Editor of The Lancers.

SIR,-The beginning of the provision of meals for school children has, of course, opened the question of methods to be used in selection. The public and many of its committees, accustomed to hearing evidence given by medical men on the subject of starvation and looking also to the profession to dogmatise on all aspects of dietetics, have erroneously assumed that by inspection and examination of children the medical man is able to say that one child should be fed by the ratepayers whilst another may be left to the care of its parents. Anyone with experience must be aware that this is a mistaken conclusion. Starvation may, of course, be recognised, but what is wanted in the case of the children is the recognition of underfeeding which may perhaps have cantinued only for a week or so. In the majority of cases such a diagnosis is absolutely impossible.

Weighing and measuring, however useful in providing evidence of "tendencies," give practically no certain information as to the individual. The average healthy child seems to have an extraordinary vitality and may be wrederfod, I do not say starved, for lang periods and yet remain apparently in excellent health, though it is probable that its future growth is being injuriously influenced. If measurements and appearances are not to be relied on, by what is the diagnosis to be made? Even in cases where it is obvious that the tissues of the child are not being sufficiently nourished it is always possible that the absorption from the digestive tract or metabolism is at fault. We have all seen cases of children from good homes who if dirty and idressed in rags would at first sight have been considered as insufficiently fed.

Leaving aside such cases where the appearance makes it obvious that something is wrong either with the child or its feeding there remain the underfed children of whom I - irst spoke; these, healthy in appearance, cannot be reoognised with certainty by anyone as being. insufficiently fed. IIt is possible to point out cases that should be fed but it is not possible for the medical man on inspection and examination to affirm that children are not underfed. The only possible method, if selection is to be exercised and mistakes are to be avoided, is that of visiting the homes and acquiring information there. Of course, I do not suggest that the doctor should do this.

My reason for writing this letter of truisms is that already in places where the medical men are helping in this workand it is certain they should help-there is a tendency to leave the decision on the question of feeding individual children entirely in the doctor's hands. If he reports that " there is no evidence on examination that the child A. B. is underfed" it is immediately concluded that he means that the child is sufficiently fed at the time of examination, a statement which no medical man would think of making without further information than inspection affords. The fallacy has arisen in the lay mind from the confusion of "starvation," which is recognisable, with " underfeeding," of which it i is very difficult to be certain. It seems to me important that we should make it clear that we cannot be sole judges in this matter in all cases.

I am, Sir, yours faithfully,

Blackburn, Sept. 29th, 1908.

MILES B. ARNoLd.

\section{CANTHARIDES POISONING.}

\section{To the Editor of THE LANCET.}

SrR,--Since communicating with you recentily re a case of acute cantharides poisoning in an adult, ${ }^{2}$ a second ease of a very similar nature has come under my notice and I venture therefore to record these few additional facts.

"The patient, an Austrian subject, was admitted to one of the private wards of Johannesburg Hospital on July 26th, under the care of Dr. H. B. Currie, giving a history as follows. He was taken ill on Saturday, July 18th, with (1) stabbing pain in the left side just at the costal margin, and (2) pain in the knee-joint (right). On the 24th he developed a cough, which was associated with scanty mucopurulent expectoration of a greenish tint, whilst the pain previously in existence became intensified and shortness of breath on exertion was experienced. Accordingly, he consulted a practitioner in town who advised the application of a blister. At 8 A.Mr. on the 25th a piece of plaster (emplastrum cantharidis B.P.), measuring $5 \frac{1}{2}$ inches by $4 \frac{1}{2}$ inches, was applied to the chest wall below and to the outer side of the left nipple. 13 hours afterwards (at 9 P.M.) the first symptoms appeared. The patient states that he felt a desire to pass urine every hour or so and could not keep (i.e., retain) it for a longer period. Pain was experienced at the end of the penis when the act was nearing completion; the urine voided was the colour of beetroot water. Headache developed in conjunction with the other symptoms, but there was neither vomiting nor purging; indeed, it appears that for the first 48 hours the bowels remained inactive.

On admission, on Sunday, July 26th, the physical signs indicative of disease were those of pleurisy with effusion on the left side. There was a raw surface measuring $5 \frac{1}{2}$ inches by $4 \frac{1}{2}$ inches below and to the outer surface of the nipple. The temperature was $102^{\circ} \mathrm{F}$, pulse 106, and respirations 39 per minute. The patient's tongue was heavily coated. His bowels had not been opened since the 24th. The right border of the heart extended a finger's breadth beyond the edge of the sternum; the apex beat was well defined, being visible in the fifth left interspace at a point one inch internal to the nipple line (very little displacement noted). The first and second sounds were clear at the apex and there was no-suspicion of a murmur. The belly wall was not rigid and there was a complete absence of abdominal pain and tenderness. The patient apparently did not experience pain in the region of the kidneys. There was no undue frequency of micturition though a good deal of pain of a buming nature was present just within the orifice of the wrethra towards the end of the act of micturition. The urine was'loaded with amorphous urates and red cells and yielded after careful filtration a well-defined cloud of albumin. The specific gravity of the filtered urine was 1028 , and it was acid in its reaction to litmus paper. A -subsequent analysis made on July 28th yielded results as follows : Specific gravity of filtered urine, 1027; reaction of filtered urine, acid; fairly dense cloud of albumin precipitated on warming the solution; centrifugalised deposit found to consist of amorphous urates, leucocytes, red blood cells, granular casts, and a few kidney cells. A third analysis carried out on the 30th demonstrated the existence of numerous kidney cells. The specimen of urine selected for examination proved turbid from precipitation of mucus and urates but cleared up on gently warming. Its specifie gravity was 1022 and reaction was aoid as on previous occasions. The centrifugalised sediment yielded one or two red blood corpuscles, a fair sprinkling of lemcocytes, several short granular and hyaline casts, a few epithelial cells from the urinary passages, and quite a number of renal epithelial cells with coarsely granular protoplasm, scattered and in groups of from 20 to 30 or more. On August 1st the chief change noted was a diminution in the number of formed elements. Beyond a few truncated granular casts and kidney cells all in an advanced stage of degeneration there

1 See The LaNCEY, Sept. 12th, 1908, p. 800. 